\title{
Occupation Specific or Generic Skills? Conflicting Interests of Firms and Apprentices
}

ROA-RM-2001/7E

Wendy Smits

Research Centre for Education and the Labour Market

Faculty of Economics and Business Administration

Maastricht University

Maastricht, December 2001 
ISBN 90-5321-324-4

Sec02.009.doc/Sec02.008.pdf 


\section{Contents}

Page

Abstract 1

1 Introduction 3

2 A model for occupation-specific and generic skills 5

$\begin{array}{ll}2.1 \text { The training programme } & 7\end{array}$

2.2 The social optimum $\quad 8$

3 Private training decisions 9

3.1 The training firm and the worker decide jointly on training 11

3.2 The training firm decides on training 12

$\begin{array}{ll}\text { 3.3 Training levels are decided on at the sector level } & 13\end{array}$

$\begin{array}{lll}3.4 & \text { Policy implications } & 14\end{array}$

4 Discussion 15

$\begin{array}{ll}\text { References } & 17\end{array}$

A Appendix 19

A1 Derivation of the social and private marginal returns to training 19

A2 The level of training, the size of the market and the probability that workers leave the industry 



\begin{abstract}
Firms and apprentices have conflicting interests with respect to the content of training programmes. On the basis of a model for the investment decision in occupation-specific and generic training, I will show that, in the case of imperfect competition, firms are not only unwilling to pay for generic training, they also want this component to be as low as possible because it decreases their expected returns to occupation-specific training. Therefore the generic component of the training will be below the social optimum. This underinvestment problem cannot always be solved by having the generic component fixed at the social optimum by an external training body. Fixing the generic component may negatively affect the level of occupation-specific training and decrease social welfare.
\end{abstract}

Keywords: apprenticeship training, occupation-specific skills, generic skills JEL-codes: J24, J42, J62

\title{
Acknowledgements
}

I would like to thank Lex Borghans, Arnaud Dupuy, Hans Heijke, Jim Malcomson, Margaret Stevens, Bas ter Weel and participants of the SKOPE seminar, University of Oxford, for many helpful comments. 



\section{Introduction}

In many industrialised countries, the apprenticeship system is an important route to prepare young people for the labour market. A well-known example is, of course, Germany where about $60 \%$ of all young people enter an apprenticeship (see Steedman (1993), Soskice (1994) and Casey (1986)). But also in the smaller European countries, such as Austria, Switzerland, Denmark and to a lesser extent, the Netherlands, and in Australia, the apprenticeship system is relatively strong (see for example Smits and Stromback (2001)). In Britain, the apprenticeship system has declined sharply since the late 1960s, but there has been a renewed interest in occupationoriented workplace training for young people during the last decades, resulting in the launch of the 'Modern Apprenticeship' in 1993 (Gospel (1994) and Gospel (1998)).

The advantages of the apprenticeship system are manifold. Besides the didactic advantages that workplace training may have (see for example Jacobs and Jones (1995), Rothwell and Kazanas (1994) and Nieuwenhuis and Onstenk (1994)), it also ensures a close match between acquired and required skills. Firms know better than schools which skills are needed for a specific occupation. They will respond faster to technological developments in a trade. The apprentice thus acquires skills that are actually demanded by firms. A potential risk of the apprenticeship system is, however, that the training is too narrow compared to what would be socially desirable because the training interests of firms will not always coincide with the training interests of apprentices. This is the subject of this paper.

The main part of apprenticeship training is usually occupation-specific. The apprentice learns to cut hair, do carpentry work or to print. The returns to occupation-specific training are, however, to some extent uncertain (Blossfeld (1991)). If the demand for hairdressers falls, the newly qualified hairdresser will face serious difficulties in finding a job and he/she may end up in a different occupation. The investment in hairdresser's skills is then lost. If he/she also possesses skills and knowledge to function well in other occupations or that facilitate the acquisition of new skills, part of the training investment can be recovered. Apprentices therefor have an interest in acquiring not only skills that are specific to the occupation they are trained for, but also some generic skills that have a wider applicability. Blechinger and Pfeiffer (2000) show that in Germany, occupational mobility after an apprenticeship is quite high, with circa one third of workers with an apprenticeship degree changing occupation. At the same time, "occupational change leads to a massive decline of the applicability of apprenticeship training". More than half of the workers who change occupation indicate that they cannot apply any of the skills acquired during the apprenticeship. Blechinger and Pfeiffer (2000) therefore conclude that the share of generic skills in apprenticeship training should increase. ${ }^{1}$

Examples of generic skills are academic skills such as reading, writing and Mathematics, but also basic technical skills (for the latter, see also Bishop (1995)). In fact, what skills are generic and what skills are occupation-specific also depends on the occupation concerned. Skills specific for one occupation may be considered generic for another occupation. Furthermore, it matters how broad a training occupation is defined. For example, do we consider printers as one occupation or do we consider offset printers and screen printers as two different occupations? By definition, a broad occupation has more occupation-specific skills than a narrow occupation.

\footnotetext{
${ }^{1}$ More precisely, they refer to a special type of generic skills, namely key qualifications.
} 
Specialisation is inevitable, but given the uncertainty on the future demand for occupationspecific skills, the apprentice will prefer that the training occupation is not too narrowly defined. ${ }^{2}$

Of course, a balanced distribution of occupation-specific and generic skills is not only important in apprenticeship programs but also for vocational education at schools. But the essential difference is that the core part of apprenticeship training takes place on the work floor in firms. This may have many didactic and economic advantages but the other side of the coin is that training firms have little interest in providing apprentices with more training than is needed to function well in the firm. If it is up to the employer to decide, apprentices will learn few skills that are not specific to the occupation they are trained for. Furthermore there is a risk that the training occupation will be too narrowly defined. An occupation demands a wide range of occupation-specific skills but in many firms, only a subset of these skills is needed. It is therefore dangerous to leave the decision as to the content of the training programme entirely to the firms. The problem is hardly mitigated if training decisions are made at the industry level. Oulton and Steedman (1994) argue that the content of the British Youth Training programmes is too occupation-specific due to the fact that employers have a dominant influence on the curriculum. Heijke, Borghans, and Smits (2001) argue that in the Netherlands industrial bodies that develop training programmes tend to overestimate the importance of skills that are needed in the sector but do not sufficiently take into account the occupational mobility after the apprenticeship that demands more generic skills. Although the generic training component in German training programs is relatively large compared to other countries (Oulton and Steedman (1994)) and efforts have been made over the last few decades to broaden the curriculum (Blossfeld (1991)), the problem exists even in Germany, as is shown by Blechinger and Pfeiffer (2000).

Other evidence on this issue is presented by Jonker (2001), who compared job performance, wages and career perspectives of auditors educated through a dual track and full-time educated auditors. She found that job performance of dual-track educated auditors was slightly better but that wages were in general lower. Furthermore, both job mobility and occupational mobility are much lower among dual-track educated auditors. This is an indication that dual-track educated auditors acquire more specific but less generic skills than full-time educated auditors. She therefore concludes that graduates from dual tracks should have "a comparable amount of general human capital as the graduates from full-time education". The problem here is, of course, that firms that train auditors through the dual-track system have little incentive to increase the level of generic training.

In the economic literature on training, conflicting interests of apprentices and firms with respect to the content of the training programme receive little attention. It is acknowledged that firms tend to pay too much attention to firm-specific skills (see Askildsen and Ireland (1993)), but the distinction between generic and occupation-specific skills is never made. Using a Beckerian framework, the distinction between occupation-specific and generic skills would be superfluous. Both types of skills can be used in external firms and can therefore be classified as general in the definition of Becker (1962), as opposed to (completely) firm-specific skills

\footnotetext{
${ }^{2}$ See also Schimmel (1998), who presents a theoretical model for the decision to acquire universal or specific knowledge. Workers who choose universal education are able to work in more occupations and have a higher probability of obtaining and keeping a job.
} 
that are only useful in the training firm. Training for general skills raises the market wages of workers as much as their (marginal) productivity. The training firm cannot appropriate any of the returns to general training and as a consequence will not be prepared to bear any of the training costs either. Since it is the worker who receives the benefits from training it is also the worker who has to make the training investment. If we extend this argument to occupationspecific and generic training, the conclusion will be that the firm will be indifferent between the two types of training, since both types of training only have benefits for the apprentice. As long as apprentices are not credit-constrained, they will choose the optimal level of both occupation-specific and generic skills. The underlying assumption is, however, that the market for both types of skills is perfectly competitive. As we will see, this assumption will not always hold for occupation-specific skills.

Some skills may be of use outside the training firm, but only in a limited number of firms or jobs. The usual properties for general training will not hold in this case. Stevens (1994) therefore introduces the term transferable training. She states that general training is only a special case of transferable training, which is characterised by perfect competition on the market for skills. In the case of imperfect competition between firms on the labour market, wages will not rise as much as the productivity of trained workers, which means that firms can appropriate some of the returns to training. Firms therefore have an incentive to invest in transferable training. However, not only the training firm, but also external firms will profit from the training. The training firm risks to lose its trained workers to other firms and will therefore invest less than the social optimum. In practice, there will be quite a few occupations that have only a limited market, especially those occupations that are linked very closely to a specific sector of industry. Training for those occupations will then be transferable but not general in the definition of Becker.

This paper concentrates on conflicting interests of firms and apprentices with respect to the training level for occupation-specific and generic skills. I will develop a theoretical model for the investment decision in both types of skills. I will show that, although it is socially optimal to have a generic training component, firms are not only unwilling to pay for generic training, they also want this component to be as small as possible, because it offers the worker better outside opportunities and forces firms in the training sector to pay higher wages. Therefore, the generic component of training will be too small as long as the worker does not participate in the training decision. Furthermore, this underinvestment problem cannot always be solved by having an external training body fix the generic component at the social optimum. Fixing the generic component may negatively affect the level of occupation-specific training and decrease social profits.

\section{A model for occupation-specific and generic skills}

I will now develop a model to investigate the optimal investment in occupation-specific and/or generic skills and identify the circumstances which may hinder this optimal investment. In this model there are two sectors, a training sector where all the training takes place and a non training sector. Both occupation-specific and generic skills are transferable but each type of skills has a different market. Occupation-specific skills only have a value in the training sector. 
Examples of these skills are printing skills and hairdressing skills, but also some ICT skills, such as programming skills. Firms in the training sector may operate on the same product market. The training sector then corresponds to a specific sector of industry, for example the printing industry, but this need not necessarily be the case, as the programmer's example shows. Generic skills, on the other hand, may have some value in the training sector but they are especially useful outside the training sector. There are several reasons for this. Firstly, generic skills that facilitate the acquisition of new skills, for example learning skills, once the trade has been learned, are more important outside the training sector than inside the sector, since a worker who moves to another sector has to acquire some new skills and knowledge to function well, for example through learning by doing. ${ }^{3}$ Secondly, as mentioned above, it depends on the occupation concerned which skills can be classified as occupation-specific and which as generic. If an occupation is very narrowly defined, skills that are generic for that occupation, are probably occupation-specific for related occupations, as the example of the offset and screen printers shows. Although offset printers may need some basic skills of screen printing, these skills are particularly important when they switch occupations, for example to become screen printers.

The mechanism of the model is as follows. The market for occupation-specific skills is relatively small and therefore the value of the occupation-specific component of the training is uncertain ex ante. Furthermore, due to (small) variations in production techniques between firms and in talent between workers, this value may differ between firms. So, it may happen that occupation-specific training is worth more in some other firm in the training sector than in the training firm. These properties give rise to imperfect competition for occupation-specific skills. The market for generic skills is very large and is characterised by perfect competition.

As firms in the training sector have some monopsony power, the post-training wages of workers in the training sector will be below their (marginal) productivity. For firms this wedge between wages and productivity is an incentive for investing in occupation-specific training. However, as will be shown, the value of generic training will put a lower bound on the skilled wage rate in the training sector and therefore firms in the training sector want this training component to be as low as possible.

The model presented in this paper is an extension of Stevens' model for transferable training (Stevens (1994)). Stevens showed that imperfect competition for transferable skills provides an incentive for firms to invest in transferable training but at the same time fewer workers will be trained than is socially optimal because the training firm, when maximising profits, does not take into account the part of the expected return that goes to external firms. My aim, on the other hand, is to show that imperfect competition for occupation-specific skills endangers the investment in skills with a wider applicability because generic training decreases the firm's expected return to occupation-specific training. The main difference between both models is that Stevens considers only one type of transferable training while in my model there is a distinction between two types of transferable training each of which has a different market. The occupation-specific component in my model is comparable to the transferable training component in Steven's model, the generic training component is new.

\footnotetext{
${ }^{3}$ There may be an overlap between the two sectors, as generic skills may be useful in some firms in the training sector but in different occupations. This will not affect the results of the model.
} 


\subsection{The training programme}

Training may take place in any firm in the training sector. There are $n$ firms operating in the training sector. The number of firms outside this sector is very large. Initially, there are many identical untrained workers in the economy. Assuming constant returns to labour, I will consider the training decision of a single firm and worker. The world lasts two periods. The sequence of events is as follows: At the beginning of period one, it is decided how much training the worker will receive. Training takes place during the first period. During the second period, the worker will work for the firm that offers him the highest wages. This may be a firm in the training sector or, alternatively, a firm outside the sector.

The training may consist of an occupation-specific part $h$ that has only value in the training sector and a generic part $a$ that has some value in the training sector but the value outside the training sector will in general exceed the value in the training sector. The value of occupationspecific training is uncertain ex ante, because firms in the sector are subject to productivity or demand shocks. There are two types of shocks, a sector-specific shock that affects all firms in the training sector in the same way and a firm-specific shock. If all firms in the training sector operate on the same product market, an example of a sector-specific shock is a fall in the demand for this product. But even if they operate on different product markets they may be subject to similar shocks since they demand the same skills and thus have to some extent similar production techniques. So a sector-specific shock may also be caused by a rise in the price of some means of production (other than labour) that is used by all firms in the training sector. The actual value of occupation-specific training will differ between firms due to firm-specific shocks. These firm-specific shocks reflect ex ante uncertainty in the match between the skills needed in the firm and the skills the worker actually possesses. An occupation demands a range of skills, but not all skills are equally important in all firms in the training sector. At the same time, some workers will turn out to be better in one skill and others in other skills. It depends on the relative importance of the various techniques in a firm and the talent of the worker, how productive a trained worker will eventually be in a certain firm.

The firm-specific shocks $\varepsilon_{i}$ are independent and identically distributed with zero mean, finite support $[-\bar{\varepsilon}, \bar{\varepsilon}]$ and continuous distribution and density functions $F($.$) and f($.$) . The sector-$ specific shock $\eta$ has support $\langle-\infty, \infty\rangle$ and continuous distribution and density functions $G($. and $g($.$) . The assumptions on the support of the sector-specific and firm-specific shocks ensure$ that there is always a positive chance that the worker will leave the training sector.

The productivity of a trained worker in a firm $i$ in the training sector is given by:

$$
\tilde{v}_{i}=h+(1-\delta) a+\varepsilon_{i}+\eta=v_{i}+(1-\delta) a
$$

where $\delta$ is a measure for the usefulness of generic skills in the training sector, $0 \leq \delta \leq 1$. For $\delta=1$ generic skills are of no use in the training sector and for $\delta=0$ generic skills are fully usable in the training sector. It is supposed that generic skills can always be fully used outside the training sector. The productivity of the worker in any firm outside the training sector is thus given by $a$.

Training costs depend on the level of both occupation-specific and generic training. The cost function is defined by $C(h, a)$. This function is increasing and convex in $h$ and $a$, so $\frac{\partial C}{\partial h}>0$, $\frac{\partial^{2} C}{\partial h^{2}}>0, \frac{\partial C}{\partial a}>0, \frac{\partial^{2} C}{\partial a^{2}}>0$. Also, there may be some interaction between $h$ and $a$ on the 
cost side. A higher level of generic skills (for example better reading skills) may facilitate the learning process of occupation-specific skills. If such an interaction effect exists, it is therefore most likely negative, so I suppose that $\frac{\partial^{2} C}{\partial a \partial h} \leq 0$.

\subsection{The social optimum}

I will start by deriving the socially optimal levels of occupation-specific and generic training. The social profits of the training programme as a function of the level of occupation-specific and generic training are equal to the difference between total returns and total costs:

$$
\Pi(h, a)=R(h, a)-C(h, a)
$$

where $R(h, a)$ represents the total expected return to training. To determine the total return, recall that occupation-specific training only has a value if the worker remains in the training sector, while generic training has the highest value if the worker leaves the sector. Define $v^{1} \leq$ $v^{2} \leq \cdots \leq v^{n}$ as the order statistics corresponding to $v_{1}, v_{2}, \ldots, v_{n}$. Sector mobility is efficient if the worker's productivity outside the training sector exceeds his maximum productivity in the sector, that is $\tilde{v}^{n}<a \Leftrightarrow v^{n}<\delta a$. Perfect competition outside the training sector ensures that the second period market wage outside the sector is given by $\omega=a$. Furthermore, it is clear that the wage that the worker will be offered in the training sector will never exceed maximum productivity, $w_{2} \leq v^{n}+(1-\delta) a$. So, for $v^{n}<\delta a$ we have $w_{2}<a$. The worker will then leave the training sector. If, on the other hand, $v^{n} \geq \delta a$ the firm in the training sector in which the worker has the highest productivity will attract the worker and make positive profits by offering a wage slightly above the worker's highest alternative. Therefore we have for $v^{n} \geq \delta a$ that $w_{2} \geq a$. The wage offered in the training sector thus ensures that separation is always efficient, that is if $v^{n}<\delta a$ the worker leaves the training sector otherwise he stays and works in the firm with the highest match. Note that the level of generic training ensures the worker a certain minimum wage for the second period.

The expected total return is given by:

$$
R=E\left[v^{n}+(1-\delta) a \mid v^{n} \geq \delta a\right] \operatorname{Pr}\left[v^{n} \geq \delta a\right]+a \operatorname{Pr}\left[v^{n}<\delta a\right]
$$

and the probability that a worker will leave the training sector by:

$$
\begin{aligned}
\operatorname{Pr}\left[v^{n}<\delta a\right] & =\operatorname{Pr}\left[v^{n}<\delta a, \eta>\delta a-h-\bar{\varepsilon}\right]+\operatorname{Pr}[\eta<\delta a-h-\bar{\varepsilon}] \\
& =\int_{\delta a-h-\bar{\varepsilon}}^{\infty} F^{n}(\delta a-h-\eta) g(\eta) \mathrm{d} \eta+G(\delta a-h-\bar{\varepsilon})
\end{aligned}
$$

since for $\eta<\delta a-h-\bar{\varepsilon}$ the maximum productivity in the training sector is always below the productivity outside the sector $\left(\operatorname{Pr}\left[v^{n}<\delta a \mid \eta<\delta a-h-\bar{\varepsilon}\right]=1\right)$. If the sector-specific shock is sufficiently small, the firm-specific shock has no effect on the probability of moving. The probability of moving is decreasing in $h$ and increasing in $a$.

It can be shown that the marginal total return to occupation-specific training is equal to the probability that the worker stays in the sector and the marginal total return to generic training equal to the value of a unit of generic training in the training sector, $1-\delta$, plus $\delta$ times the 
probability he moves to another sector ${ }^{4}$. Maximising social profits (equation 2) with respect to $h$ and $a$, we find that the socially optimal training levels $\left(h^{*}, a^{*}\right)$ are the ones that provide

$$
\begin{aligned}
& \frac{\partial C}{\partial h}=\operatorname{Pr}\left[v^{n} \geq \delta a\right] \\
& \frac{\partial C}{\partial a}=1-\delta+\delta \operatorname{Pr}\left[v^{n}<\delta a\right]
\end{aligned}
$$

Note that if $\varepsilon$ and $\eta$ were both degenerate at zero and generic training only had value outside the training sector (e.g. $\delta=1$ ), it would be socially optimal to specialise in the skill type that can be acquired at the lowest cost.

How is this social optimum affected by the size of the market? The higher the degree of competition, the higher the probability that there is a firm in the training sector in which the value of a trained worker is above the value outside the sector (see the appendix).

$$
\frac{\partial \operatorname{Pr}\left[v^{n}<\delta a\right]}{\partial n}<0
$$

The probability of moving to another sector decreases with the size of the market. If the number of firms in the training sector becomes very large, there is still a positive probability that the worker will move.

$$
\lim _{n \rightarrow \infty} \operatorname{Pr}\left[v^{n}<\delta a\right]=G(\delta a-h-\bar{\varepsilon})
$$

So even if the number of firms in the training sector were very large and generic training had no value in the training sector (e.g. $\delta=1$ ), it would be socially optimal for workers to learn some generic skills. ${ }^{5}$

\section{Private training decisions}

The social optimum will only be reached if the social profits coincide with the private profits of the agents who decide on training. How are the returns to training shared between the worker, the training firm and the other firms in the training sector? To answer this question, we need to know the worker's second-period wage in the training sector. We know already that for $v^{n} \geq \delta a$ the worker will stay in the training sector and work for the firm with the highest match at a wage $w_{2}, a \leq w_{2} \leq v^{n}+(1-\delta) a$. This firm will set the wage at the lowest value that makes it possible to attract the worker. The actual wage therefore depends on $v^{n-1}$ and $a$. If $v^{n-1} \geq \delta a$ the second-period wage will be $w_{2}=v^{n-1}+(1-\delta) a$ and if $v^{n-1}<\delta a \leq v^{n}$ it will be $w_{2}=a{ }^{6}$ Table 1 summarises the different labour market outcomes.

The expected return to the worker $R_{w}$ is given by:

$$
\begin{aligned}
R_{w}= & E\left[v^{n-1}+(1-\delta) a \mid v^{n-1} \geq \delta a\right] \operatorname{Pr}\left[v^{n-1} \geq \delta a\right] \\
& +a \operatorname{Pr}\left[v^{n-1}<\delta a\right]
\end{aligned}
$$

\footnotetext{
${ }^{4}$ The derivation of the marginal total return is given in the appendix.

${ }^{5}$ As mentioned before this is due to the assumption that the sector-specific shock has no finite support while the firm-specific shock has. The outcomes of the model are, however, not affected by this assumption.

${ }^{6}$ Stevens (1994) shows that this is a Nash equilibrium.
} 
The total expected return to firms in the training sector:

$$
\begin{aligned}
R_{f}= & E\left[v^{n}-v^{n-1} \mid v^{n-1} \geq \delta a\right] \operatorname{Pr}\left[v^{n-1} \geq \delta a\right] \\
& +E\left[v^{n}-\delta a \mid v^{n-1}<\delta a \leq v^{n}\right] \operatorname{Pr}\left[v^{n-1}<\delta a \leq v^{n}\right]
\end{aligned}
$$

Since there is no firm-specific training component, ex ante all firms in the training sector have equal probability to employ the worker in the second period and the expected return for an individual firm $i$ is given by $R_{f} / n$. Note that the expected return to the training firm does not exceed the expected return to any other firm in the training sector. The return to firms outside the training sector is zero, because these firms pay the worker his full productivity.

An increase in the level of occupation-specific training increases the worker's second-period wage only if $v^{n-1} \geq \delta a$. Unless $\delta=0$, an increase in the level of generic training is only fully reflected in the wage rate if $v^{n-1}<\delta a$. For $v^{n-1} \geq \delta a$ the wage increase will be bounded by the limited usefulness of generic skills in the training sector. The return to the firm, on the other hand, is only affected by a change in the level of occupation-specific or generic training if $v^{n-1}<\delta a \leq v^{n}$. This conditional return increases in $h$ and decreases in $a$. The expected private marginal returns with respect to $h$ and $a$ are equal to: ${ }^{7}$

$$
\begin{aligned}
& \frac{\partial R_{w}}{\partial h}=\operatorname{Pr}\left[v^{n-1} \geq \delta a\right] \\
& \frac{\partial R_{w}}{\partial a}=1-\delta+\delta \operatorname{Pr}\left[v^{n-1}<\delta a\right] \\
& \frac{\partial R_{f}}{\partial h}=\operatorname{Pr}\left[v^{n-1}<\delta a \leq v^{n}\right] \\
& \frac{\partial R_{f}}{\partial a}=-\delta \operatorname{Pr}\left[v^{n-1}<\delta a \leq v^{n}\right]
\end{aligned}
$$

Note that, in contrast to Stevens (1994), part of the marginal benefits of occupation-specific training accrues to firms in the training sector. The reason for this is that in my model, due to the option to work outside the training sector, an increase in the level of occupation-specific training will not always lead to an increase in the worker's second-period wage. Black and Loewenstein (1997) and Loewenstein and Spletzer (1998) obtain a similar result for a minimumwage guarantee for the post-training period given by the training firm. They show that if the firm has to pay a certain minimum wage in the post-training period, it can increase its profits by

Table 1: Labour market outcomes

\begin{tabular}{|l|l||l|l|}
\hline \multicolumn{2}{|c||}{ productivity } & \multicolumn{2}{c|}{ returns } \\
\hline$v^{n}$ & $v^{n-1}$ & worker & firm \\
\hline \hline$v^{n}<\delta a$ & & $a$ & 0 \\
\hline$v^{n} \geq \delta a$ & $v^{n-1}<\delta a$ & $a$ & $v^{n}-\delta a$ \\
\hline$v^{n} \geq \delta a$ & $v^{n-1} \geq \delta a$ & $v^{n-1}+(1-\delta) a$ & $v^{n}-v^{n-1}$ \\
\hline
\end{tabular}

\footnotetext{
${ }^{7}$ The appendix provides the derivations.
} 
increasing the productivity of the worker by just as much as is possible without increasing the chance that the worker will leave the training firm. Acemoglu and Pischke (1999) also show that the existence of a minimum wage provides an incentive for firms to provide transferable training to increase the worker's productivity level to the level of the minimum wage. In this respect, the outside option for the worker in our model, $\omega=a$, acts as a minimum wage, but while in Acemoglu and Pischke (1999) this minimum wage is exogenously given, here it is endogenous to the model as it depends on the level of generic training. As long as $v^{n-1}<\delta a \leq v^{n}$, the worker stays in the training sector and the firm that employs him has to pay a wage equal to $a$, in which case the conditional return increases in $h$. The marginal return to occupation-specific training as a function of the level of generic training attains a maximum for some $a \geq 0$. As the level of generic training increases, the chance that the worker will be paid the minimum-wage guarantee increases, but the chance that the worker will stay in the training sector decreases. If the chance that the worker will stay in the training sector approaches zero, for example if $a$ becomes very large, the effect of the minimum-wage guarantee on $h$ diminishes. Note that for $\delta=0$, the effect of the outside option is independent of $a$. Generic training is worth just as much in the training sector as outside the training sector, but the option to leave the training sector still acts as a minimum-wage guarantee.

For $\delta>0$, the marginal return to generic training for the firms in the training sector is negative. Given the level of occupation-specific training, an increase in the level of generic training increases the outside option for workers more than their productivity in the training sector and thus decreases the expected returns to firms.

The marginal private returns are clearly affected by the size of the market. We have:

$$
\operatorname{Pr}\left[v^{n-1}<\delta a \leq v^{n}\right]=\int_{\delta a-h-\bar{\varepsilon}}^{\infty} n F^{n-1}(\delta a-h-\eta)(1-F(\delta a-h-\eta)) g(\eta) \mathrm{d} \eta
$$

It is easy to see that:

$$
\lim _{n \rightarrow \infty} \operatorname{Pr}\left[v^{n-1}<\delta a \leq v^{n}\right]=0
$$

The marginal return to the firms in the training sector fades if $n$ becomes very large. Furthermore, since

it follows that

$$
\operatorname{Pr}\left[v^{n-1}<\delta a\right]=\operatorname{Pr}\left[v^{n}<\delta a\right]+\operatorname{Pr}\left[v^{n-1}<\delta a \leq v^{n}\right]
$$

$$
\lim _{n \rightarrow \infty} \operatorname{Pr}\left[v^{n-1}<\delta a\right]=\lim _{n \rightarrow \infty} \operatorname{Pr}\left[v^{n}<\delta a\right]
$$

The private marginal benefit of occupation-specific and generic training of the worker approaches the social marginal benefits if $n$ becomes very large, which is the situation Becker (1964) refers to.

In the following subsections, I will consider the training outcomes if (1) the training firm and the worker decide jointly on training, (2) the training firm decides alone on the level of training, and (3) the training levels are decided at the sector level.

\subsection{The training firm and the worker decide jointly on training}

Suppose that the training firm and the worker decide jointly on the levels of occupation-specific and generic training. Their joint private optimum is given by: 


$$
\begin{aligned}
& \frac{\partial C}{\partial h}=\frac{1}{n} \operatorname{Pr}\left[v^{n} \geq \delta a\right]+\frac{n-1}{n} \operatorname{Pr}\left[v^{n-1} \geq \delta a\right] \\
& \frac{\partial C}{\partial a}=1-\delta+\delta\left(\frac{1}{n} \operatorname{Pr}\left[v^{n}<\delta a\right]+\frac{n-1}{n} \operatorname{Pr}\left[v^{n-1}<\delta a\right]\right)
\end{aligned}
$$

Comparing this private optimum with the social optimum given by (5) and (6), it is clear that for $\frac{\partial^{2} C}{\partial a \partial h}=0$ and $\delta>0$ the level of generic training will be too high and the level of occupationspecific training will be too low. The private marginal returns to occupation-specific training are below the social marginal return while the private marginal return to generic training is above the private marginal return. The reason for this is that the return to the other firms in the training sector is not incorporated in the training decision. The worker always wants more generic training than is socially optimal because the level of generic training puts a lower bound on the wage he will be paid during the second period, irrespective of whether he stays in the training sector or moves. For the same reason, the training firm wants to offer less generic training but since the firm only accounts for its own loss and not for the loss of external firms its weight in the training decision is low compared to that of the worker. Furthermore, the worker want less occupation-specific training than is socially optimal because it will only increase his expected future wage if not only his maximum productivity $\left(v^{n}\right)$ exceeds his outside productivity but also the second-best match $\left(v^{n-1}\right)$. If the second-best match does not exceed his outside value, the extra returns accrue to the firm that will employ him. This latter result is in contrast with Stevens's model where, as mentioned before, the marginal benefits of transferable training fully accrue to the worker and, as a consequence, the choice of the level of occupation-specific training is not directly affected by the externality. ${ }^{8}$ This externality disappears if the number of firms becomes very large since $\lim _{n \rightarrow \infty} \operatorname{Pr}\left[v^{n-1} \geq \delta a\right]=\lim _{n \rightarrow \infty} \operatorname{Pr}\left[v^{n} \geq \delta a\right]$. For $\frac{\partial^{2} C}{\partial a \partial h}<0$ the underinvestment in $h$ will be less severe since overinvestment in $a$ will decrease the marginal costs of $h$.

Note that for $\delta=0$, the expected wage increase is equal to the expected increase in productivity, both within and outside the training sector. In that case, the private optimal level of generic training will be equal to the social optimum if $\frac{\partial^{2} C}{\partial a \partial h}=0$ and will be below the social optimum if $\frac{\partial^{2} C}{\partial a \partial h}<0$.

\subsection{The training firm decides on training}

Workers will only participate in the training decision if they share in the training costs. There are circumstances in which workers are not able or not willing to do so. For example, if workers are credit-constrained or if they have insufficient information on the quality of the training (see Malcomson, Maw, and McCormick (1997) and Smits (1997)). If the training firm decides on its own on the training level, no generic training will take place since training firms are only interested in occupation-specific training. More precisely, the private optimum in this case is given by:

\footnotetext{
${ }^{8}$ Although it might be indirectly affected through the costs function.
} 


$$
\begin{aligned}
& \frac{\partial C}{\partial h}=\frac{1}{n}\left(\operatorname{Pr}\left[v^{n} \geq \delta a\right]-\operatorname{Pr}\left[v^{n-1} \geq \delta a\right]\right) \\
& \frac{\partial C}{\partial a}=\delta \frac{1}{n}\left(\operatorname{Pr}\left[v^{n}<\delta a\right]-\operatorname{Pr}\left[v^{n-1}<\delta a\right]\right)
\end{aligned}
$$

Since the right-hand side of (22) is negative or zero and $\frac{\partial C}{\partial a}>0$, there is no internal solution for $a$. A corner solution is given by $a=0$. The training firm provides no generic training since generic training lowers the expected future profits of the training firm. Compared to the social optimum, the level of occupation-specific training is affected in three ways. Firstly, the training firm does not allow for the expected parts of the returns to occupation-specific training that accrue to other firms in the training sector $\left(\frac{n-1}{n}\left(\operatorname{Pr}\left[v^{n} \geq \delta a\right]-\operatorname{Pr}\left[v^{n-1} \geq \delta a\right]\right)\right)$ and to the apprentice $\left(\operatorname{Pr}\left[v^{n-1} \geq \delta a\right]\right)$. This direct effect is negative. Secondly, the level of generic training indirectly affects the level of occupation-specific training. The level of generic training acts as a minimum-wage guarantee and given that firms in the training sector have to pay this minimum wage, profits can be increased by increasing the level of occupation-specific training. A decrease in a may either increase or decrease the marginal return to occupation-specific training since it lowers the minimum-wage guarantee but also leads to less sectoral mobility. Therefore, this second effect may be either positive or negative. It is negative if

$$
\operatorname{Pr}\left[v^{n} \geq 0\right]-\operatorname{Pr}\left[v^{n-1} \geq 0\right]<\operatorname{Pr}\left[v^{n} \geq \delta a^{*}\right]-\operatorname{Pr}\left[v^{n-1} \geq \delta a^{*}\right]
$$

This means that for $a=a^{*}$, there is a higher chance that a firm in the training sector will employ the worker and pay the minimum-wage guarantee $w_{2}=a$ than for $a=0$. Note that for $\delta=0$ this second effect does not occur. In that case, the lower bound on the second-period wages does not depend on the actual level of generic training. Thirdly, if $\frac{\partial^{2} C}{\partial a \partial h}<0$, there is another indirect effect of the level of generic training on the level of occupation-specific training. Since a lower level of $a$ increases the (marginal) costs of occupation-specific training, this effect is negative. The lower the level of generic training, the higher the marginal costs of occupationspecific training. If the second effect is positive and outweighs the first and third effect, the private optimum for $h$ will be above the social optimum, otherwise it will be below it.

From (21) it follows that if the number of firms in the training sector becomes very large, it will be optimal not to provide any occupation-specific training at all. It is only profitable for the firm to provide occupation-specific training if competition is less than perfect.

\subsection{Training levels are decided on at the sector level}

Since all firms in the training sector may profit from the training, the expected profits for the sector may increase if training decisions take place on the sector level. This situation is quite common in several countries, notably in the Netherlands and to a lesser extent in Germany. Suppose as before that workers do not pay for their training. Also suppose that there is a coordinating body that first decides on the level of training and then levies a training contribution of $\frac{1}{n} C(h, a)$ to all firms in the training sector. Firms that train are refunded the training costs. So, all firms pay an equal amount of the costs of training workers, irrespective of where this training takes place. The co-ordinating body decides on the training levels by maximising 
profits at the sector level. The optimal levels of occupation-specific and generic training for the training sector are given by:

$$
\begin{aligned}
& \frac{\partial C}{\partial h}=\operatorname{Pr}\left[v^{n} \geq \delta a\right]-\operatorname{Pr}\left[v^{n-1} \geq \delta a\right] \\
& \frac{\partial C}{\partial a}=\delta\left(\operatorname{Pr}\left[v^{n}<\delta a\right]-\operatorname{Pr}\left[v^{n-1}<\delta a\right]\right)
\end{aligned}
$$

Again, there is no internal solution for $a$ and a corner solution is that no generic training will be provided. The level of occupation-specific training is higher than in the case in which each firm decides on its own on training levels since the expected profits of all firms are now taken into account in the training decision. Whether the level of occupation-specific training will be below or above the social optimum, depends on the indirect effect of a lower level of $a$ on $h$ through the marginal returns to $h$ and through the cost function. For $\frac{\partial^{2} C}{\partial a \partial h}=0$ the private optimal level of occupation-specific training will be above the social optimum if $\operatorname{Pr}\left[v^{n} \geq 0\right]-\operatorname{Pr}\left[v^{n-1} \geq 0\right]>\operatorname{Pr}\left[v^{n} \geq \delta a^{*}\right]$.

If the number of firms becomes very large, the returns to the training sector vanish. In that case, all returns go to the workers and as a consequence it is not profitable to finance training on the sector level either.

\subsection{Policy implications}

Since private training decisions do not result in the socially optimal level of occupation-specific and generic training, if competition is imperfect, we will now examine whether social profits can be increased by government intervention. I consider the situation in which firms are free to decide on the level of occupation-specific training but the level of generic training is fixed by a social planner. Another course of action is to deprive the training sector of all influence on the training programme and fix both $a$ and $h$ at the socially optimal level. The training sector will, however, have better insight in what skills are needed in the sector than a social planner. Indeed, one of the advantages of the apprenticeship system is a close match between the skills required and the skills acquired. It is not unlikely that a social planner simply lacks good knowledge of $h$. Taking away all influence of firms may therefore have other disadvantages.

The point of departure is the situation in which training decisions are taken at the sector level. In this case, no generic training will be provided and the level of occupation-specific training will be either too high or too low compared to the social optimum, depending on the indirect effects of a lower $a$ on $h$ through the marginal return to $h$ and through the cost function. Now suppose that the level of generic training is exogenously fixed by a social planner. What is the optimal intervention level for $a$, that is what level of generic training will maximise social profits given that the level of occupation-specific training is determined at the sector level? The private optimal level of occupation-specific training for the training sector as a function of the level of generic training $h(a)$ follows from equation (23). Substituting for $h(a)$ in the social profit function (equation 6 ), and differentiating with respect to $a$, gives the first-order condition for the socially optimal level of $a$ :

$$
\frac{\partial C}{\partial a}=1-\delta+\delta \operatorname{Pr}\left[v^{n}<\delta a\right]+\frac{d h}{d a}\left(\operatorname{Pr}\left[v^{n} \geq \delta a-\frac{\partial C}{\partial h}\right]\right)
$$


substituting for equation (23) in (25) gives:

$$
\frac{\partial C}{\partial a}=1-\delta+\delta \operatorname{Pr}\left[v^{n}<\delta a\right]+\frac{d h}{d a} \operatorname{Pr}\left[v^{n-1} \geq \delta a\right]
$$

The optimal intervention level of generic training $\hat{a}$ depends clearly on the sign of $\frac{d h}{d a}$ and on $\frac{\partial^{2} C}{\partial a \partial h}$. First suppose that $\frac{\partial^{2} C}{\partial a \partial h}=0$. Then for $\frac{d h}{d a}<0$ the optimal intervention level of generic training is below the social optimum, $\hat{a}<a^{*}$ and for $\frac{d h}{d a}>0$ it is above the social optimum $\hat{a}>a^{*}$. If the level of generic training does not affect the level of occupation-specific training, that is, if $\frac{d h}{d a}=0$, the external body should set the level of generic training equal to the social optimum, $\hat{a}=a^{*}$. This is always the case if $\delta=0$, that is, if generic training has the same value within the training sector as outside the training sector.

If $\frac{\partial^{2} C}{\partial a \partial h}<0$, intervention is even more complicated. In that case, we have $\hat{a}<a^{*}$ even for $\frac{d h}{d a}=0$. If $\frac{d h}{d a}>0$, the optimal intervention level of generic training may be above or below the social optimum, depending on the size of both indirect effects of $a$ on $h$.

So, for government intervention to be successful, we need a good insight in the different effects of intervention. Intervention on the generic component of training will affect sectoral mobility and wages after the training and therefore has an indirect effect on the level of occupationspecific training as well. Higher sector mobility will discourage investments in occupationspecific training while a higher minimum wage will encourage these investments. Which effect dominates depends on the cost function and on the distribution of the sector-specific and firmspecific shocks. In general, it is not optimal to set the level of generic training simply at the social optimum $a^{*}$. Any positive effect of an increase in $a$ on social profits may then be offset by the decrease in $h$, in which case public intervention worsens the situation.

\section{Discussion}

In this paper, we considered two types of skills, occupation-specific skills, which only have a value in one particular sector of Industry, and generic skills, which have a value in a number of sectors. If the market for both types of skills were perfectly competitive, these could both be classified as general in the definition of Becker. In that case, workers would pay the costs of both types of training and choose the optimal mix of occupation-specific and generic training. Things are different, however, if the market for occupation-specific skills is limited. Imperfect competition for occupation-specific skills gives monopsony power to firms in the training sector, who can appropriate some of the returns to occupation-specific training. As a consequence, firms in the training sector are prepared to bear part of the costs of occupation-specific training. However, the expected returns to firms decrease with the level of generic training. This is because the expected future wages that firms in the training sector have to pay increase more with the level of generic training than the expected productivity of the workers. More generic training thus directly lowers the expected profits of firms in the training sector. So firms are not only unwilling to pay for generic training, they also want this training component to be as small as possible. It follows that firms and workers have opposite interests with respect to generic training. Workers want more generic training than is socially optimal at a given level of 
occupation-specific training, while firms want less generic training. Private training decisions will therefore generate either too little or too much generic training.

This model predicts that the apprenticeship system will flourish especially in occupations that have a strong link with a particular economic sector, such as carpenters and hairdressers. Apprentices in these occupations learn skills that only have a value in the building industry or in the hairdressing sector. Due to imperfect competition, firms in these sectors can appropriate some of the returns to training and are therefore prepared to invest in apprenticeship training. Furthermore, firms in these sectors are interested in co-ordinating their training activities. The returns to training for an individual firm may not be very high, since a worker may quit to work for another firm in the same sector, but for the sector as a whole they certainly are. On the contrary, the apprenticeship system will do less well in occupations that have no strong link with any particular economic sector, such as many administrative occupations, since these occupations have a larger market. Firms that train apprentices for these occupations will not share in the profits. In the Netherlands, we see indeed that the apprenticeship system is well represented in occupations that have a close link to a particular sector of industry, while the apprenticeship system for administrative occupations has not been very successful, not in the last place because the availability of apprenticeship places falls short of the demand and is of low quality. Not surprisingly, full-time education is still the dominant trajectory for administrative occupations.

But, as shown in this paper, a strong sector link will also have some disadvantages. Firms are not prepared to supply training that is useful outside the sector of industry. An example is the Dutch printing industry. Traditionally, the apprenticeship system is very well developed in this branch of industry. With the digitisation of the production process, many skills needed in the traditional printing industry are now also of use outside this industry in the so-called graphical periphery (multimedia, copying, design, and advertising)(Teunen (1997)). As a consequence, the returns to training for firms in the printing industry have declined and the number of training places has fallen.

If decisions on the content of the training programme are taken on the sector level, there is a risk that the training programme is too narrow and only aimed at the needs of the sector. The policy implications of my model for the apprenticeship system are, however, not straightforward. It is clear that the industry should not be free to set the entire training programme. However, having the generic component of the training fixed by an external body may have a negative effect on the size of the occupation-specific component, since it increases occupational mobility. Public intervention will then lower social profits. Intervention therefore demands a thorough knowledge of the interaction effects of generic and occupation-specific training. 


\section{References}

Acemoglu, D., And J. Pischke (1999): "The Structure of Wages and Investment in General Training," Journal of Political Economy, 107(3), 539-72.

Askildsen, A., And N. Ireland (1993): "Human Capital, Property Rights and Labour Managed Firms," Oxford Economic Papers, 45, 229-42.

Becker, G. (1962): "Investment in Human Capital: A Theoretical Analysis," Journal of Political Economy, 70(supplement), 9-49.

(1964): Human Capital, A Theoretical and Empirical Analysis with Special Reference to Education. The University of Chicago Press, Chicago.

Bishop, J. (1995): "Expertise and Excellence," Working Paper 95-13, Center for Advanced Human Resource Studies, Ithaca, New York.

Black, D., and M. Loewenstein (1997): "Dismissals and Match-Specific Rents," Labour Economics, 4, 325-40.

Blechinger, D., And F. Pfeiffer (2000): "Technological Change and Skill Obsolesence: The Case of German Apprenticeship Training," in Education and Training in a KnowledgeBased Economy, ed. by H. Heijke, and J. Muysken, chap. 10, pp. 243-276. Macmillan Press Ltd, Houndmills/London.

Blossfeld, H.-P. (1991): "Is the German Dual System a Model for a Modern Vocational Training System?," EUI Working Paper SPS 91/7, European University Institute, Florence, Department of Political and Social Sciences.

Casey, B. (1986): "The Dual Apprenticeship System and the Recruitment and Retention of Young Persons in West Germany," British Journal of Industrial Relations, 24(1), 63-81.

Gospel, H. F. (1994): "The Survival of Apprenticeship Training: A British, American, Australian Comparison," British Journal of Industrial Relations, 32(4), 505-22.

(1998): "The Revival of Apprenticeship Training," British Journal of Industrial Relations, 36(3), 435-57.

Heiske, H., L. Borghans, And W. Smits (2001): "De WEB tussen vraag en aanbod," Report, Stuurgroep Evaluatie WEB.

Jacobs, R. L., And M. Jones (1995): Structured On-The-Job Training. Unleashing Employee Expertise in the Workplace. Berret-Koehler Publishers, San Fransisco.

Jonker, N. (2001): Job Performance and Career Prospects of Auditors, vol. 253 of Tinbergen Insitute Research Series. Thela Thesis, Amsterdam.

Loewenstein, M., and J. Spletzer (1998): "Dividing the Costs and Returns to General Training," Journal of Labor Economics, 16(1), 142-71. 
Malcomson, J., J. Maw, and B. McCormick (1997): "General Training by Firms, Contract Enforceability and Public Policy," Discussion Paper 21, University of Southampton.

Nieuwenhuis, L., and J. Onstenk (1994): "Werkend Leren in Opleiding En Beroep: De Werkplek Als Krachtige Leeromgeving," Comenius, 14, 198-219.

Oulton, N., And H. Steedman (1994): "The British System of Youth Training: A Comparison with Germany," in Training and the Private Sector: International Comparisons, ed. by L. M. Lynch, pp. 61-76, Chicago and London. National Bureau of Economic Research, University of Chicago Press, Comparative Labor Markets Series.

Rothwell, W. J., and H. Kazanas (1994): Improving on-the-Job Training. How to Establish and Operate a Comprehensive OJT Program. Jossey Bass, San Francisco.

Schimmel, U. (1998): "The Educational Choice: Universal or Specific?," Discussion Paper 558-98, Universitat Mannheim. Institut fur Volkswirtschaftslehre und Statistik.

Smits, W. (1997): "Apprenticeship Training under Imperfect Information," Discussion paper, paper presented to the 1997 EALE Conference, Århus.

Smits, W., and T. Stromback (2001): The Economics of the Apprenticeship System. Edward Elgar, Cheltenham.

Soskice, D. (1994): "Reconciling Markets and Institutions: The German Apprenticeship System," in Training and the Private Sector: International Comparisons, ed. by L. M. Lynch, pp. 25-60, Chicago and London. National Bureau of Economic Research, University of Chicago Press, Comparative Labor Markets Series.

Steedman, H. (1993): "The Economics of Youth Training in Germany," Economic Journal, 103, 1279-91.

Stevens, M. (1994): "A Theoretical Model of on-the-Job Training with Imperfect Competition," Oxford Economic Papers, 46(4), 537-62.

Teunen, J. (1997): "Werkend Leren in de Grafische Industrie," report, GOC, Veenendaal. 


\section{A Appendix}

\section{A.1 Derivation of the social and private marginal returns to training}

Define $\varepsilon^{1} \leq \varepsilon^{2} \leq \cdots \leq \varepsilon^{n}$ as the order statistics corresponding to $\varepsilon_{1}, \varepsilon_{2}, \ldots, \varepsilon_{n}$. The distribution functions of $\varepsilon^{n}$ and $\varepsilon^{n-1}$ are given by $F_{n}()=.F(.)^{n}$ and $F_{n-1}()=.F(.)^{n}+n F(.)^{n-1}(1-F()$. and the density functions by $f_{n}()=.n f(). F(.)^{n-1}$ and $f_{n-1}()=.n(n-1) f(). F(.)^{n-2}(1-F()$.$) .$ The joint density of $\varepsilon^{n}$ and $\varepsilon^{n-1}$ is given by $f_{n, n-1}(y, z)=n(n-1) F(z)^{n-2} f(z) f(y)$. The probability of leaving the training sector is given by:

$$
\begin{aligned}
\operatorname{Pr}\left[v^{n}<\delta a\right] & =\iint_{y+\eta<\delta a-h} f_{n}(y) g(\eta) \mathrm{d} \eta \\
& =\int_{-\infty}^{\infty} F^{n}(\delta a-h-\eta) g(\eta) \mathrm{d} \eta \\
& =\int_{\delta a-h-\bar{\varepsilon}}^{\infty} F^{n}(\delta a-h-\eta) g(\eta) \mathrm{d} \eta+G(\delta a-h-\bar{\varepsilon})
\end{aligned}
$$

and the probability that the worker remains in the training sector and earns wages equal to the market wages outside the training sector is given by:

$$
\begin{aligned}
\operatorname{Pr}\left[v^{n-1}<\delta a \leq v^{n}\right] & =\iiint_{\eta+z<\delta a-h<\eta-y} n(n-1) F(z)^{n-2} f(z) f(y) g(\eta) \mathrm{d} \eta \\
& =\int_{-\infty}^{\infty} n F^{n-1}(\delta a-h-\eta)(1-F(\delta a-h-\eta)) g(\eta) \mathrm{d} \eta \\
& =\int_{\delta a-h-\bar{\varepsilon}}^{\infty} n F^{n-1}(\delta a-h-\eta)(1-F(\delta a-h-\eta)) g(\eta) \mathrm{d} \eta
\end{aligned}
$$

Expected total returns to training are equal to:

$$
\begin{aligned}
R= & E\left[v^{n}+(1-\delta) a \mid v^{n} \geq \delta a\right] \operatorname{Pr}\left[v^{n} \geq \delta a\right]+a \operatorname{Pr}\left[v^{n}<\delta a\right] \\
= & \int_{-\infty}^{\infty} \int_{\delta a-h-\eta}^{\bar{\varepsilon}}(h+(1-\delta) a+y+\eta) f_{n}(y) g(\eta) \mathrm{d} y \mathrm{~d} \eta \\
& +a \int_{-\infty}^{\infty} F_{n}(\delta a-h-\eta) g(\eta) \mathrm{d} \eta
\end{aligned}
$$

Differentiation of this expression with respect to $h$ and $a$ gives

$$
\begin{aligned}
\frac{\partial R}{\partial h} & =\int_{-\infty}^{\infty}\left(1-F^{n}(\delta a-h-\eta)\right) g(\eta) \mathrm{d} \eta=\operatorname{Pr}\left[v^{n} \geq \delta a\right] \\
\frac{\partial R}{\partial a} & =(1-\delta) \int_{-\infty}^{\infty}\left(1-F^{n}(\delta a-h-\eta)\right) g(\eta) \mathrm{d} \eta+\int_{-\infty}^{\infty} F^{n}(\delta a-h-\eta) g(\eta) \mathrm{d} \eta \\
& =1-\delta+\delta \operatorname{Pr}\left[v^{n}<\delta a\right]
\end{aligned}
$$


Private returns to the worker are given by

$$
\begin{aligned}
R_{w}= & E\left[v^{n-1}+(1-\delta) a \mid v^{n-1} \geq \delta a\right] \operatorname{Pr}\left[v^{n-1} \geq \delta a\right]+a \operatorname{Pr}\left[v^{n-1}<\delta a\right] \\
= & \int_{-\infty}^{\infty} \int_{\delta a-h-\eta}^{\bar{\varepsilon}}(h+(1-\delta a)+z+\eta) f_{n-1}(z) g(\eta) \mathrm{d} z \mathrm{~d} \eta \\
& +a \int_{-\infty}^{\infty} F_{n-1}(\delta a-h-\eta) g(\eta) \mathrm{d} \eta
\end{aligned}
$$

and private marginal returns to the worker by

$$
\begin{aligned}
\frac{\partial R_{w}}{\partial h}= & \int_{-\infty}^{\infty}\left(1-n F^{n-1}(a-h-\eta)\left(1-F^{n}(\delta a-h-\eta)\right)-F^{n}(\delta a-h-\eta)\right) g(\eta) \mathrm{d} \eta \\
= & \operatorname{Pr}\left[v^{n-1}>\delta a\right] \\
\frac{\partial R_{w}}{\partial a}= & 1-\delta+\delta \int_{-\infty}^{\infty}\left(n F^{n-1}(a-h-\eta)\left(1-F^{n}(a-h-\eta)\right)\right. \\
& \left.+F^{n}(a-h-\eta)\right) g(\eta) \mathrm{d} \eta \\
= & 1-\delta+\delta \operatorname{Pr}\left[v^{n-1}<a\right]
\end{aligned}
$$

Total private returns to firms in the training sector are given by

$$
\begin{aligned}
R_{f}= & E\left[v^{n}-v^{n-1} \mid v^{n-1} \geq \delta a\right] \operatorname{Pr}\left[v^{n-1} \geq \delta a\right] \\
& +E\left[v^{n}-\delta a \mid v^{n-1}<\delta a \leq v^{n}\right] \operatorname{Pr}\left[v^{n-1}<\delta a \leq v^{n}\right] \\
= & \int_{-\infty}^{\infty} \int_{\delta a-h-\eta}^{\bar{\varepsilon}} \int_{z}^{\bar{\varepsilon}} n(n-1)(y-z) F(z)^{n-2} f(z) f(y) g(\eta) \mathrm{d} y \mathrm{~d} z \mathrm{~d} \eta \\
& +\int_{-\infty}^{\infty} \int_{z}^{\bar{\varepsilon}} n(h-\delta a+y+\eta) F^{n-1}(\delta a-h-\eta) f(y) g(\eta) \mathrm{d} y \mathrm{~d} \eta
\end{aligned}
$$

and total private marginal returns to firms in the training sector by

$$
\begin{aligned}
\frac{\partial R_{f}}{\partial h} & =\int_{-\infty}^{\infty} n F^{n-1}(\delta a-h-\eta)\left(1-F^{n}(\delta a-h-\eta)\right) g(\eta) \mathrm{d} \eta \\
& =\operatorname{Pr}\left[v^{n-1}<\delta a<v^{n}\right] \\
\frac{\partial R_{f}}{\partial a} & =-\delta \int_{-\infty}^{\infty} n F^{n-1}(\delta a-h-\eta)\left(1-F^{n}(\delta a-h-\eta)\right) g(\eta) \mathrm{d} \eta \\
& =-\delta \operatorname{Pr}\left[v^{n-1}<\delta a<v^{n}\right]
\end{aligned}
$$


A.2 The level of training, the size of the market and the probability that workers leave the industry

The probability of leaving the training sector, $\operatorname{Pr}\left[v^{n}<\delta a\right]$, decreases in $h$ and $n$ and increases in $a$ since

$$
\begin{aligned}
& \frac{\partial \operatorname{Pr}\left[v^{n}<\delta a\right]}{\partial h}=-\int_{\delta a-h-\bar{\varepsilon}}^{\infty} f_{n}(\delta a-h-\eta) g(\eta) \mathrm{d} \eta \leq 0 \\
& \frac{\partial \operatorname{Pr}\left[v^{n}<\delta a\right]}{\partial a}=\int_{\delta a-h-\bar{\varepsilon}}^{\infty} f_{n}(\delta a-h-\eta) g(\eta) \mathrm{d} \eta \geq 0 \\
& \frac{\partial \operatorname{Pr}\left[v^{n}<\delta a\right]}{\partial n}=-\int_{\delta a-h-\bar{\varepsilon}}^{\infty} \log \left(F(\delta a-h-\eta) F^{n}(\delta a-h-\eta) g(\eta) \mathrm{d} \eta \leq 0\right.
\end{aligned}
$$

